\title{
Modulation of phycobiliprotein production in N ostoc muscorum through culture manipulation
}

\author{
Onkar Nath Tiwari ${ }^{1 *}$, Wangkhem Indira Devi ${ }^{1}$, Chungkham Silvia ${ }^{1}$, Angom Thadoi Devi ${ }^{1}$, Gunapati Oinam ${ }^{1}$, Oinam \\ Avijeet Singh ${ }^{1}$, Keithellakpam Ojit Singh ${ }^{1}$, Thingujam Indrama ${ }^{1}$, Aribam Subhalaxmi Sharma ${ }^{1}$, Romi Khangembam ${ }^{1}$, \\ Minerva Shamjetshabam ${ }^{1}$, Longjam Miranda, Radha Prasanna ${ }^{2}$ \\ ${ }^{1 *}$ National Repository for Cyanobacteria and Microgreen algae (Freshwater), Microbial Resources Division, Institute of Bioresources and Sustainable \\ Development, Takyelpat, Imphal-795001, Manipur, India. ${ }^{2}$ Division of Microbiology, ICAR- IARI, New Delhi, India.
}

\begin{tabular}{|c|c|}
\hline ARTICLE INFO & BSTRACT \\
\hline $\begin{array}{l}\text { history: } \\
\text { d on: } 04 / 06 / 2015 \\
\text { on: } 17 / 06 / 2015 \\
\text { d on: } 24 / 07 / 2015 \\
\text { le online: } 24 / 08 / 2015\end{array}$ & \multirow{2}{*}{$\begin{array}{l}\text { Nostoc sp. BTA87 was procured from National fresh water cyanobacterial and microalgal repository of IBSD- } \\
\text { DBT, Imphal, Manipur, India. This was identified as Nostoc muscorum based upon morphological characteristics } \\
\text { and 16S rRNA gene sequence analysis. Cultivation of organism under two cultural conditions indicated that } \\
\text { phycobiliproteins enhanced under dialyzed conditions in comparison to non-dialyzed conditions. Red light was } \\
\text { more effective to green and blue light for enhanced production of phycocyanin and allophycocyanin whereas } \\
\text { phycoerythrin was produced more under green light in dialyzed condition. The optimum pH for maximum } \\
\text { production of all the three components of phycobiliproteins was } 8.0 \text {. The results clearly indicated that the } \\
\text { production of phycobiliproteins can be enhanced by cultivating cyanobacterium in dialyzed conditions at pH- } 8.0 \\
\text { under optimum light quality and Nostoc muscorum can be a potential candidate for the commercial production of } \\
\text { phycobiliproteins. }\end{array}$} \\
\hline $\begin{array}{l}\text { dialyzed culture, } \mathrm{pH} \text {, light } \\
\text { quality, Nostoc muscorum, } \\
\text { phycobiliproteins }\end{array}$ & \\
\hline
\end{tabular}

\section{INTRODUCTION}

Cyanobacterial phycobiliproteins have gained considerable importance in the commercial sector. In general, cyanobacteria remain as potential sources for further investigations as prospective and excellent sources of biologically active constituents produced during primary and especially secondary metabolism [1].

Phycobiliproteins from these organisms show potential applications as natural food colorants. These are common lightharvesting proteins with chromatic sensors, which are non-toxic and non-carcinogenic natural food colorants, a much needed alternative to the widely used synthetic food colorants/additives having toxicity and carcinogenicity [2]. Besides food and drug industry, these also have potential in cosmetic preparations by replacing the synthetic dyes [3]. The potential of cyanobacteria for commercial production of phycobiliproteins has been reported by many workers [2, 4, 5]. Environmental variables particularly light can influence the rate of photosynthesis and growth of cyanobacteria as these are photoautotrophs [6].

* Corresponding Author

Mail id: ontiwari1968@gmail.com

Mobile No.: +919862564743

Telefax: $+91385-2446120 / 21 / 22$
Light quality has been reported to have a strong influence on light harvesting system of these organisms [7, 8, 9]. When exposed to different light colors, many cyanobacterial species are able to adjust the composition of their phycobiliproteins through a process known as chromatic acclimation or adaptation [10].

In addition to light, the $\mathrm{pH}$ of the medium determine diversity, distribution, abundance and growth of cyanobacteria in various freshwater and terrestrial ecosystems, and also influence the metabolic or biochemical activities in laboratory cultures [11, 12]. This variable can also influence the composition and content of phycobiliproteins. Modulation of the environmental variables can influence and in turn regulate the biomass productivity and phycobiliprotein yield.

Dialyzed cultures typically exhibit high rates of photosynthesis and growth, besides a considerable increase in the duration of the stationary stage.

The small volume of the dialysis bag also helps to maintain high concentrations of physiologically active cells, which are promising for diverse applications. In view of this, present study was undertaken to analyze the effect of different quality of light and $\mathrm{pH}$ on phycobiliprotein production from Nostoc muscorum under dialyzed condition. Microscopy and 16S rRNA gene sequencing was also carried out for the authentic identification of the studied organism. 


\section{MATERIALS AND METHODS}

\subsection{Organism and growth conditions}

Nostoc sp. BTA87 was procured from the Freshwater cyanobacterial and microalgal repository (National Facility, Department of Biotechnology, Govt. of India) of IBSD, Imphal, Manipur, India. A known biomass of Nostoc sp. BTA87 was inoculated in nitrogen deficient BG-11 $(-\mathrm{N})$ medium and incubated for 15 days under standard cultural conditions. Fresh biomass from exponentially grown cultures was harvested by centrifugation at $5800 \mathrm{X} \mathrm{g}$ for $10 \mathrm{~min}$ and incubated in dialysis bag prepared using dialysis membrane (Dialysis membrane-110, 32.34*21.5 mm, HiMedia, India) submerged in aspirator bottle containing known volume of same medium. For control conditions, similar amount of biomass was inoculated directly in the aspirator bottle having BG-11 (-N) medium. Growth was determined through chlorophyll$a$ estimation [13] under dialyzed and non-dialyzed conditions.

\subsection{Microscopic observations, 16S rRNA gene sequencing and phylogenetic tree construction}

The purity of the obtained strain was checked microscopically using Carl Zeiss fluorescence microscope, Axio Scope A1 coupled with Carl Zeiss software AxioVision 4.7.2 followed by taxonomical characterization following standard keys [14]. The identification was authenticated by using 16S rRNA gene sequencing. Genomic DNA was isolated according to the modified xanthogenate method [15]. Partial 16S rRNA gene sequence was amplified employing universal primers (Integrated DNA Technology, India) namely 536F 5'GTGCCAGCAGCCGCGGTRATA-3' and 1488R 5'CGGTTACCTTGTTACGACTTCA CC-3' [16]. A total of $50 \mu \mathrm{l}$ of PCR reaction mixture was prepared having $5 \mu$ of $1 \mathrm{X}$ Taq buffer, $5 \mu \mathrm{l}$ of $200 \mu \mathrm{M}$ of each deoxynucleotide, $1.5 \mu \mathrm{l}$ of $0.3 \mu \mathrm{M}$ of each forward and reverse primer, $0.25 \mu \mathrm{l}$ of $5 \mathrm{U}$ Taq DNA polymerase and $2 \mu \mathrm{l}$ of DNA extract. The PCR conditions were set for 28 cycles with initial denaturation at $95^{\circ} \mathrm{C}$ for $5 \mathrm{~min}$ then final denaturation of $95^{\circ} \mathrm{C}$ for $1 \mathrm{~min}$, annealing at $55^{\circ} \mathrm{C}$ for $1 \mathrm{~min}$ and final extension at $72^{\circ} \mathrm{C}$ for 2 min using Thermal cycler (Mastercycler gradient, Eppendorf, Germany). The PCR product was detected with standard agarose gel electrophoresis (Elchrom Scientific GEPS 200/2000, Switzerland) and quantification of PCR product was done with Biospectrometer (Eppendorf, Germany). Sequencing of the quantified $16 \mathrm{~S}$ rRNA PCR product was done at National Centre for Cell Science (NCCS), Pune, India and subsequently, BLAST analysis (http://www.ncbi.nlm.nih.gov) was carried out. Neighbour Joining method was used for analysis of 16S rRNA gene sequence and phylogenetic tree construction by Kimura 2-parameter taking 1000 replicates as bootstrap value by using MEGA 4.0 software [17] and Synechococcus sp. PCC7918 was used as an outgroup taxa.

\subsection{Extraction and estimation of phycobiliproteins}

Biomass was harvested from 30 days old culture by centrifugation at $5800 \mathrm{X} \mathrm{g}$ for $10 \mathrm{~min}$ and phycobiliproteins were extracted following the method of [7] using phosphate buffer ( $\mathrm{pH}$ 7.0) and repeated freezing and thawing. The concentration of phycocyanin (PC), allophycocyanin (APC) and phycoerythrin (PE) was determined spectrophotometrically (UV-1800 Spectrophotometer, Shimadzu, Japan) in the supernatant and quantified ( $\mu \mathrm{g} / \mathrm{mg}$ of fresh biomass) as given under

$\mathrm{PC}=\left(\mathrm{A}_{615^{-}}-0.474 \times \mathrm{A}_{652}\right) / 5.34$ where, 5.34 = extinction co-

efficient

$\mathrm{APC}=\left(\mathrm{A}_{652}-0.208 \times \mathrm{A}_{615}\right) / 5.09$ where, $5.09=$ extinction coefficient

$\mathrm{PE}=\left[\mathrm{A}_{562^{-}}\{2.41(\mathrm{PC})\}-\{0.849(\mathrm{APC})\}\right] / 9.62$ where, $9.62=$ extinction co-efficient

\subsection{Phycobiliprotein production under varied light quality and pH of the medium}

To understand the effect of different light quality on phycobiliprotein production, a known amount of wet biomass placed inside the dialysis bag was put into aspirator bottles wrapped with green, yellow, red and blue cellophane papers. One aspirator bottle was kept uncovered under same experimental conditions to represent the control. Incubation was done at $28 \pm 2{ }^{\circ} \mathrm{C}$ under a light intensity of $54-67 \mu \mathrm{mol}$ photon $\mathrm{m}^{2} / \mathrm{s}$ with 14/10 h light and dark period provided by cool white fluorescent tubes fitted with photoperiodic timer (Saveer Biotech Limited, India) coupled with room temperature controller. The same experimental condition was set up with varying $\mathrm{pH}(6.5,7.0,7.5$, 8.0 and 8.5) of culture medium to study its effect on phycobiliprotein production. The medium was changed daily to allow continuous supply of nutrients for the growing culture.

\section{RESULTS}

\subsection{Microscopic observations, 16S rRNA gene sequencing and phylogenetic tree construction}

The identification of the studied organism was confirmed as Nostoc muscorum on the basis of microscopic parameters. It exhibited a filamentous habit with distinct sheath only at the periphery of the thallus and the thallus was dark green in color, gelatinous-membranous, irregularly expanded. Thalli were tuberculate and attached at the lower surface. Cells were cylindrical $(5.23 \times 5.20 \mu \mathrm{m})$, rarely barrel shape with intercalary and spherical heterocysts $(4.05 \times 3.45 \mu \mathrm{m})$ with the ends rounded (Figure 1).

A total of 6 partial 16S rRNA gene sequences of same strains and 2 sequences each of Anabaena sp. and Calothrix sp. were retrieved from the NCBI GenBank database and the $16 \mathrm{~S}$ rRNA partial sequence compared with the representative cyanobacterium (Figure 2). A BLAST search performed resulted in the highest similarity score $(97 \%)$ of Nostoc muscorum with Nostoc sp. PCC9426 and the topology was supported with a bootstrap value. The cluster was well supported by bootstrap analysis and partly reflected the morphological similarity of the organisms. The results indicated that the strains of Anabaena sp. were genetically closer. The distance in the tree indicated the 
evolutionary relationships between the studied strain and Nostoc sp. originating from distinct geographical sites. Microscopic observations and 16S rRNA gene sequence authenticated the identification of the cyanobacterium as Nostoc muscorum. The partial 16S rRNA gene sequence was submitted to NCBI GenBank (accession number KF953527).

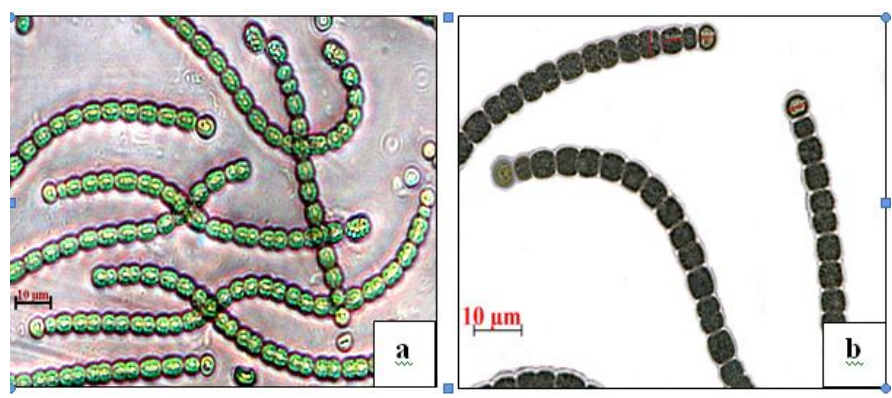

Fig. 1: Photomicrographs of Nostoc muscorum under (a) 40x magnification (b) 100x magnification with scale bars.

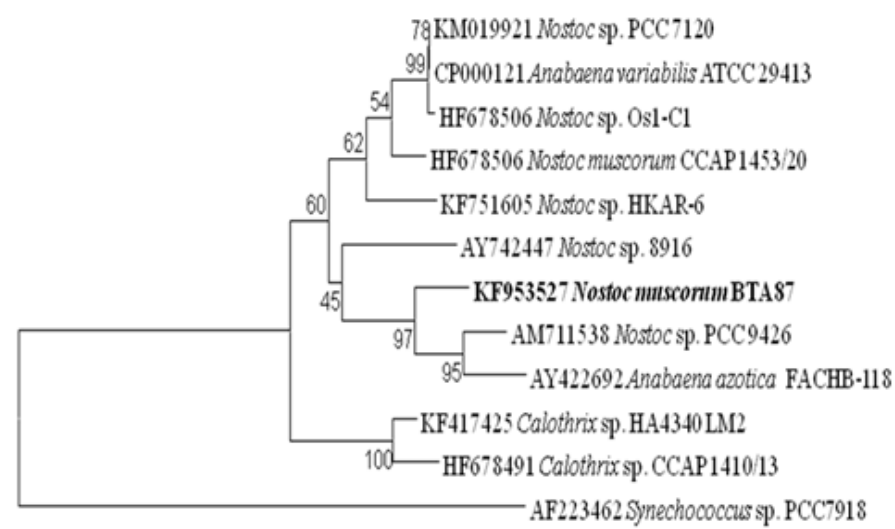

\subsection{1}

Fig. 2: Neighbour joining tree based on partial $16 \mathrm{~S}$ rRNA gene sequence. The tree includes sequence of cyanobacterial strain determined in the present study (bold) and 10 sequences from NCBI GenBank and accession number of each taxa is also included. Bootstrap values (1000 replicates) greater than $40 \%$ are indicated at the nodes. The scale bar indicates 0.01 substitution per nucleotide position.

\subsection{Phycobiliprotein production in dialyzed culture and non- dialyzed culture}

The organism exhibited an exponential phase from 7 days till 15 days followed by a stationary phase after 20 days of incubation. In the present study, 30 days old dialyzed culture was used to assess the growth and phycobiliprotein production. Total phycobiliproteins production was higher in dialyzed culture $(235.91 \mu \mathrm{g} / \mathrm{mg})$ than non-dialyzed culture $(86.86 \mu \mathrm{g} / \mathrm{mg})$.

\subsection{Effect of light quality on phycobiliprotein production}

The quality of light for the cultivation influenced the phycobiliprotein production significantly. Red light showed higher production of phycocyanin $(84.94 \mu \mathrm{g} / \mathrm{mg})$, allophycocyanin $(33.71$ $\mu \mathrm{g} / \mathrm{mg})$ followed by phycocyanin (81.66 $\mu \mathrm{g} / \mathrm{mg})$ and allophycocyanin $(33.29 \mu \mathrm{g} / \mathrm{mg})$ production in green light. Allophycocyanin production $(27.78 \mu \mathrm{g} / \mathrm{mg})$ was reduced in blue light. The phycoerythrin production was high in green light (3.87 $\mu \mathrm{g} / \mathrm{mg}$ ) than red light $(2.46 \mu \mathrm{g} / \mathrm{mg})$ (Table 1$)$.

Table 1: Influence of light quality on the production of phycobiliprotein components in Nostoc muscorum

\begin{tabular}{llllll}
\hline $\begin{array}{c}\text { Pigment } \\
(\boldsymbol{\mu g} / \mathbf{m g})\end{array}$ & $\begin{array}{c}\text { White } \\
\text { light }\end{array}$ & $\begin{array}{c}\text { Green } \\
\text { light }\end{array}$ & $\begin{array}{c}\text { Blue } \\
\text { light }\end{array}$ & $\begin{array}{c}\text { Red } \\
\text { light }\end{array}$ & $\begin{array}{c}\text { Yellow } \\
\text { light }\end{array}$ \\
\hline Phycocyanin & 55.86 & 81.66 & 71.79 & 84.94 & 67.01 \\
& \pm 5.12 & \pm 4.45 & \pm 5.02 & \pm 4.52 & \pm 4.66 \\
\hline Phycoerythrin & 03.68 & 02.46 & 02.47 & 03.87 & 03.43 \\
& \pm 3.28 & \pm 2.07 & \pm 2.10 & \pm 2.05 & \pm 2.15 \\
\hline Allophycocyanin & 17.32 & 33.29 & 27.78 & 33.29 & 27.64 \\
& \pm 3.05 & \pm 3.15 & \pm 3.25 & \pm 3.30 & \pm 4.22 \\
\hline
\end{tabular}

\subsection{Effect of pH on phycobiliprotein production}

A pH of 8.0 was observed to be optimum (PC-325.00 $\mu \mathrm{g} / \mathrm{mg}$, APC-208.02 $\mu \mathrm{g} / \mathrm{mg}$ and PE-55.75 $\mu \mathrm{g} / \mathrm{mg}$ ) for highest production of different components of phycobiliproteins in Nostoc muscorum (Figure 3). The phycobiliproteins production was lowest at a $\mathrm{pH}$ of 6.5 (PC-55.86 $\mu \mathrm{g} / \mathrm{mg}$, APC-17.32 $\mu \mathrm{g} / \mathrm{mg}$ and PE-13.68 $\mu \mathrm{g} / \mathrm{mg}$ ) and at $\mathrm{pH} 8.5$, the components of phycobiliproteins decreased and varied (PC-279.24 $\mu \mathrm{g} / \mathrm{mg}$, APC$121.82 \mu \mathrm{g} / \mathrm{mg}$ and PE-49.37 $\mu \mathrm{g} / \mathrm{mg}$ ).

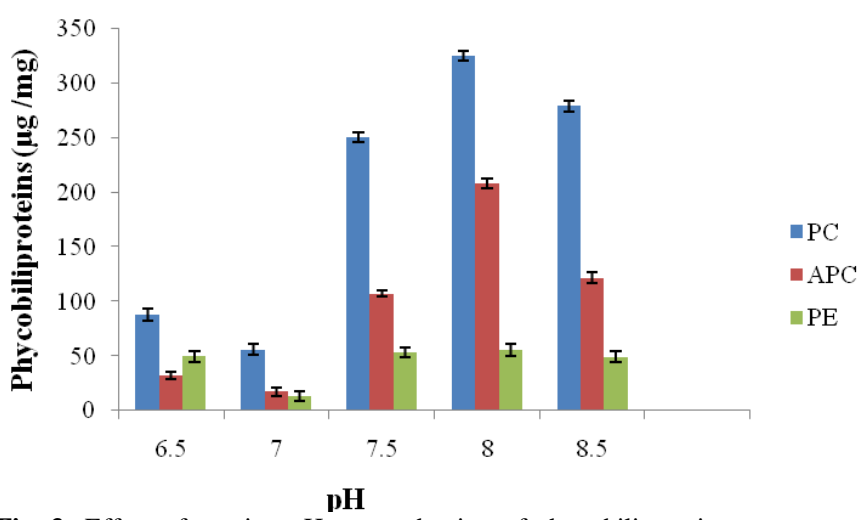

Fig. 3: Effect of varying $\mathrm{pH}$ on production of phycobiliprotein components PC, APC, PE ( $\mu \mathrm{g} / \mathrm{mg}$ fresh biomass) in Nostoc muscorum

\section{DISCUSSION}

Phycobiliproteins have been reported to have immense potential for use in the pharmaceutical and food industries [18, 19, 20, 21]; however their economically viable production on a large scale has been a challenging endeavour. The identification of the experimental organism was authenticated by microscopic examination and 16S rRNA gene sequence analysis. The identified organism as Nostoc muscorum showed $97 \%$ similarity with Nostoc sp. PCC 9426 and the clustering was well supported by bootstrap analysis.

In the present study, the effect of light quality and $\mathrm{pH}$ on phycobiliprotein production was investigated in Nostoc muscorum KF953527 cultivated in dialysis bags. Dialysis cultivation technique was adopted since it adds to the enhancement of total phycobiliproteins production which yield higher amount (235.91 $\mu \mathrm{g} / \mathrm{mg}$ ) than non-dialyzed culture $(86.86 \mu \mathrm{g} / \mathrm{mg})$. Cultivation of cyanobacteria in dialysis bag enhanced stationary phase of the culture and increased the yield of phycobiliproteins. It is well 
known that a culture grown in dialysis bag is characterized by an increased duration of the stationary phase and some physiological parameters, such as the rate of photosynthesis and concentrations of pigments are enhanced during the course of experiment [22]. It was reported that upto $80 \%$ of the population of Anacystis nidulans in a batch culture after reaching the stationary phase was represented by an increased content of dead cells whereas dialysis culture consisted of metabolically active cells [23].

The analysis of components of phycobiliprotein indicated the influence of the quality of light on phycobiliprotein production. The phycocyanin $(84.94 \mu \mathrm{g} / \mathrm{mg})$ and allophycocyanin (33.71 $\mu \mathrm{g} / \mathrm{mg}$ ) contents were higher under red light, however, the phycoerythrin $(3.87 \mu \mathrm{g} / \mathrm{mg})$ content was more in green light. Therefore, the studied strain Nostoc muscorum adjusts the phycobiliproteins composition in response to the light quality, in order to use the light source most effectively for photosynthesis and other related activities. The results are in accordance with the reports on Nostoc flagelliforme by [24] as large number of cyanobacteria can change their composition of photosynthetic pigments by chromatic adaptation as these organisms have probably evolved mechanisms to modify their photosynthetic machinery in response to spectral quality of light. [25, 26] reported white light for Anabaena sp. and green light for Nostoc sp. as most promising for the phycobiliproteins synthesis. Light shift from white light to red light increased the phycocyanin and chlorophylla synthesis of Anacystis nidulans [27]. Phycocyanin production showed a maximum induction of 3.3 fold under red light in Fremyella diplosiphon [28]. Red light grown cultures of Calothrix sp. (strain 7601) and Spirulina platensis also showed enhanced phycobiliprotein production [26, 29]. Red light or blue light was essential for phycocyanin production of Synechococcus sp. NKBG 042902 [5]. Similar findings were obtained in Westiellopsis iyengarii [30], where the phycocyanin production was high in red light $(0.005 \mu \mathrm{g} / \mathrm{mg})$. Similar result was also obtained in the present study, that the culture grown in white light produced $55.86 \mu \mathrm{g} / \mathrm{mg}$ and increased the production of phycocyanin upto $84.94 \mu \mathrm{g} / \mathrm{mg}$ after the red light treatment. The study by [31] reported that phycocyanin, allophycocyanin and phycoerythrin was abundant in both Synechococcus sp. (3.389 $\mu \mathrm{g} / \mathrm{mg}, 3.143 \mu \mathrm{g} / \mathrm{mg}$ and 2.621 $\mu \mathrm{g} / \mathrm{mg})$ and Anabaena sp. (2.894 $\mu \mathrm{g} / \mathrm{mg}, 2.712 \mu \mathrm{g} / \mathrm{mg}$ and 2.835 $\mu \mathrm{g} / \mathrm{mg}$ ) respectively in red light treatment. The results of marine cyanobacterium Pseudanabaena sp. (32) coincided with the present study showed highest phycocyanin production (14.9 $\mu \mathrm{g} / \mathrm{mg}$ ) during red light treatment which gradually decreased in green $(3.7 \mu \mathrm{g} / \mathrm{mg})$, blue $(3.5 \mu \mathrm{g} / \mathrm{mg})$ and white $(2.1 \mu \mathrm{g} / \mathrm{mg})$ light grown conditions. Similar results have been reported by (32) in which phycoerythrin production was found to be highest $(0.04$ $\mu \mathrm{g} / \mathrm{mg})$. The effect of chromatic light on phycobiliproteins induction was reported as strain specific [25, 26]. Most cyanobacteria optimized the harvesting of light for available irradiance and spectral composition by modulating their antenna pigments which assures photoprotection. Changes in the pigment composition are usually due to differences in the relative rate of synthesis and total amount of phycobiliproteins [33].
Phycobilisomes adapt to the quality of light, through a complex process, which enable them to change the phycocyanin/ phycoerythrin composition so that the available wavelengths can be efficiently absorbed [34]. Green light was seen to be suitable for enhanced phycoerythrin synthesis in Nostoc muscorum. The results suggest that Nostoc muscorum can modulate the synthesis of PC and PE in order to use the available light optimally and APC-containing core structures of phycobilisomes do not appear to change significantly during chromatic adaptation. In another study, [35] reported that allophycocyanin synthesis was independent to spectral light. In contrast to the present findings, [36] showed that phycocyanin synthesis in Nostoc sp. was highest in white light.

In summary, during complementary chromatic adaptation, only the inducible phycocyanin gene set modulates its gene expression depending on the light quality [37]. The enhanced production of different components of phycobiliproteins under different light quality is because putative photoreversible pigments respond to red and green light, and regulate the expression of phycoerythrin and phycocyanin-II operons through a system involving reversible phosphorylation of DNA-binding [38]. Regulation of phycobiliproteins expression in green light and red light requires either two different photoreversible photoreceptors or a common photoreceptor that initiates two significantly different signal transduction pathways [27]. The results suggest that Nostoc muscorum can modulate the synthesis of phycocyanin and phycoerythrin in order to use the available light optimally and allophycocyanin-containing core structures of phycobilisomes do not appear to change significantly during chromatic adaptation.

$\mathrm{pH}$ is an important factor which not only determines diversity, distribution, abundance and growth of cyanobacteria in various freshwater and terrestrial ecosystems, but also influence their metabolic or biochemical activities considerably in laboratory cultures $[11,12]$.

Highest production of phycobiliproteins was recorded at an optimum $\mathrm{pH}$ of 8.0 in Nostoc muscorum; this finding was consistent with the reports on Synechocystis sp. [39], Anabaena NCCU-9 [25]. The $\mathrm{pH}$ was considered as an important factor in regulating phycobiliprotein production in Synechocystis PCC6701 and Gloeocapsa [40]. On the other hand, the increase in $\mathrm{pH}$ from 7.0 to 9.0 can increase the total phycobiliprotein content in Nostoc sp. UAM206 [41] and the cyanobacteria are known to prefer neutral to slightly alkaline $\mathrm{pH}$ for optimum growth [42]. The extreme $\mathrm{pH}$ may cause internal electrostatic attraction by changing the charge on protein giving net positive charge and at this stage protein can open up and bound solvent is lost which results in the denaturation of proteins [43].

\section{CONCLUSIONS}

The present study clearly indicated that the production of phycobiliproteins $(235.91 \mu \mathrm{g} / \mathrm{mg})$ in dialysis bag grown cultures was more as compared to non-dialyzed culture $(86.86 \mu \mathrm{g} / \mathrm{mg})$ during the stationary phase than the culture grown in normal 
control conditions. Nostoc muscorum adapted chromatically and produced more phycocyanin and phycoerythrin in red light and allophycocyanin in green and red light. An increase in biomass and phycobiliproteins of this organism was observed under $\mathrm{pH}$ 8.0. This study provides valuable information for upscaling of optimized protocols in terms of light quality and $\mathrm{pH}$ of medium for commercial production of phycobiliproteins.

\section{ACKNOWLEDGEMENTS}

We all authors express our sincere thanks to the Director, DBT-IBSD, Imphal, Manipur, India for providing laboratory facilities and the Department of Biotechnology, Government of India for financial assistance.

\section{REFERENCES}

1. Skulberg OM. Microalgae as a source of bioactive moleculesexperience from cyanophyte research. Journal of Applied Phycology. 2000; 12: 341-348.

2. Chaneva G, Furnadzhieva S, Minkova K, Lukavsky J. Effect of light and temperature on the cyanobacterium Arthronema africanum- a prospective phycobiliprotein-producing strain. Journal of Applied Phycology. 2007; 19: 537-544.

3. Soni B, Kalavadia B, Trivedi U, Maddamwar D. Extraction purification characterization of phycocyanin from Oscillatoria quadripunctula- isolated from the rocky shores of Bet Dwarka, Gujarat, India. Process Biochemistry. 2006; 41: 2017-2023.

4. Chen F, Zhang Y, Guo S. Growth and phycocyanin formation of Spirulina platensis in photoheterotrophic culture. Biotechnology Letters. 1996; 18: 603-608.

5. Takano H, Arai T, Hirano M, Matsunaga T. Effect of intensity and quality of light on phycocyanin production by a marine cyanobacterium Synechococcus sp. NKBG042902. Applied Microbiology and Biotechnology. 1995; 43: 1014-1018.

6. Andrian GB, David MK. Emerging perspectives on the mechanisms, regulation, and distribution of light color acclimation in cyanobacteria. Molecular Plant. 2012; 5(1):1-13.

7. Bennett A, Bogorad L. Complementary chromatic adaptation in a filamentous blue-green alga. Journal of Cell Biology. 1973; 58: 419435.

8. Korbee N, Figueroa FL, Aguilera J. Effect of light quality on the accumulation of photosynthetic pigments, proteins and mycosporinelike amino acids in the red alga Porphyra leucosticta (Bangiales, Rhodophyta). Journal of Photochemistry and Photobiology. B: Biology. 2005; 80: 71-78.

9. Prasanna R, Pabby A, Saxena S, Singh PK. Modulation of pigment profiles of Calothrix elenkenii in response to environmental stresses. Journal of Plant Physiology. 2004; 161: 1125-1132.

10. Kehoe DM, Gutu A. Responding to colour: the regulation of complementary chromatic adaptation. Annual Review of Plant Biology. 2006; 57: 127-150.

11. Whitton BA. Soils and rice-fields, Their Diversity in Time and Space. In: Whitton BA, Potts M, editors. The Ecology of Cyanobacteria, Kluwer Academic Publishers, Dordrecht, The Netherlands; 2000, p. 233-255.

12. Rafiqul IM, Jalal KCA, Alam MZ. Environmental factors for optimization of Spirulina biomass in laboratory culture. Biotechnology. 2005; 4: 19-22.

13. Mckinney G. Absorption of light by chlorophyll solution. Journal of Biological Chemistry. 1941; 140: 315-322.

14. Desikachary TV. Cyanophyta. Indian Council of Agricultural Research. New Delhi; 1959

15. Avijeet SO, Oinam G, Singh KO, Tiwari ON. Isolation of fresh water cyanobacterial DNA of north east India by modified Xanthogenate method. International Journal of Research BioScience. 2013; 2(2): 75-82.

16. Nubel U, Garcia-Pichel F, Muyzer G. PCR primers to amplify $16 \mathrm{~S}$ rRNA genes from cyanobacteria. Applied and Environmental Microbiology. 1997; 63(8): 3327-3332.

17. Tamura K, Dudley J, Nei M, Kumar S. MEGA4: Molecular Evolutionary Genetics Analysis (MEGA) software version 4.0. Molecular Biology and Evolution. 2007; 24(8): 1596-1599.

18. Prasanna R, Sood A, Suresh A, Nayak S, Kaushik BD. Potentials and applications of algal pigments in biology and industry. Acta Botanica Hungarica. 2007; 49: 131-156.

19. Benedetti S, Benvenuti F, Pagliarani S, Francogli S, Scoglio S, Canestrari F. Antioxidant properties of a novel phycocyanin extract from the blue-green alga Aphanizomenon flos-aquae. Life Science. 2004; 55: 2353-2362.

20. Dufossea L, Galaupa P, Yaronb A, Aradb SM, Blancc P, Murthyd KNC, Ravishankard GA. Microorganisms and microalgae as sources of pigments for food use: A scientific oddity or an industrial reality. Trends in Food Science and Technology. 2005; 16: 389- 406. doi:10.1016/j.tifs.2005.02.006.

21. Santiago-Santos MC, Ponce-Noyola T, Olvera-RamI-rez R, OrtegaLopez J, Canizares-Villanueva RO. Extraction and purification of phycocyanin from Calothrix sp. Process Biochemistry. 2004; 39: 2047-2052. doi:10.1016/j.procbio.2003.10.007.

22. Savanina YaV, Lebedeva AF, Barsky EL. Dialysis cultivation of cyanobacteria. Moscow University Biological Sciences Bulletin. 2008; 63 (2): 62-71.

23. Gusev MV, Lebedeva AF, Savanina YaV, Barsky EL. Resistance of cultures of cyanobacterium Anacystis nidulans and microalga Dunaliella maritime to toxic influence of Vanadium. Effects of Phosphate, Iron and Cysteine. Moscow University Biological Sciences Bulletin. 1997; 3: 12-17.

24. Dai Y-J, Jing L, Shu-Mei W, Nan C, Yu-Peng X, Zhi-Lei T, Shi-Ru J, Nan-Nan Y, Ning T, Yi-Jie S. Effect of light with different wavelengths on Nostoc flagelliforme cells in liquid culture. Journal of Microbiology and Biotechnology. 2013; 23(4): 534-538.

25. Hemlata AE, Fatma T. Screening of cyanobacteria for phycobiliproteins and effect of different environmental stress on its yield. Bulletin of Environmental Contamination and Toxicology. 2009; 83: 509-515.

26. Rodriguez H, Rivas J, Guerrer MG, Manuel-Losada M. Enhancement of phycobiliprotein production in nitrogen-fixing cyanobacteria. Journal of Biotechnology. 1991; 20: 263-270.

27. Lonneborge A, Lind LK, Kalla SR, Gustafsson P, Oquist G. Acclimation process in the light-harvesting system of cyanobacterium Anacystis nidulans following a light shift from white to red light. Plant Physiology. 1985; 78: 110-114.

28. Kilani J, Lebeault JM. Study of the oxygen transfer in a disposable flexible bioreactor with surface aeration in vibrated medium. Applied Microbiology and Biotechnology. 2007; 74: 324-330.

29. Stowe WC, Brodie-Kommit J, Stowe-Evans E. Characterization of complementary chromatic adaptation in Gloeotrichia UTEX 583 and identification of a transposon-like insertion in the cpeBA operon. Plant Cell Physiology. 2011; 52(3): 553-562.

30. Ashok Kumar P, Anand N. Studies on growth and phycobilin pigments of the cyanobacterium Westiellopsis iyengarii. International Journal of Biotechnology and Biochemistry. 2010; 6(2): 315-323.

31. Elumalai S, Rajesh KG, Jegan G, Sangeetha T, Roop SD. Extraction of phycocyanin an important pharmaceutical phycobiliproteins from cyanobacteria. International Journal of Pharmaceutical Research and Development. 2014; 6(4): 67-74

32. Mishra SK, Shrivastava A, Maurya RR, Patidar SK, Haldar S, Mishra S. Effect of light quality on the C-phycoerythrin production in marine cyanobacteria Pseudanabaena sp. isolated from Gujarat coast, India. Protein Expression and Purification. 2012; 81: 5-10.

33. Rafiqul Islam MD, Hassan A, Sulebele G, Orosco C, Roustaian P. Influence of temperature on growth and biochemical composition of Spirulina platensis and S. fusiformis. Iranian International Journal of Science. 2003; 4: 97-106. 
34. Simeunovic J, Markovic S, Kovac D, Misan A, Mandic A, Svircev Z. Filamentous cyanobacteria from Vojvodina region as source of phycobiliprotein pigments as potential natural colorants. Food and Feed Research. 2012; 39 (1): 23-31

35. Tandeau De Marsac N, Houmard J. Adaptation of cyanobacteria to environmental stimuli: new steps towards molecular mechanisms. FEMS Microbiology Review. 1993; 104: 119-190.

36. Eldin MJ, Kanhaiya K, Debabrata D. Physico-chemical parameters optimization, and purification of phycobiliproteins from the isolated Nostoc sp. Bioresource Technology. 2014. 166: 541-547. doi: http://dx.doi.org/10.1016/j.biortech.2014.05.097.

37. Grossman AR. A molecular understanding of complementary chromatic adaptation. Photosynthesis Research. 2003; 76: 207-215.

38. Schyns G, Sobczyk A, Tandeau de Marsac N, Houmard J. Specific initiation of transcription at a cyanobacterial promoter with RNA polymerase purified from Calothrix sp. PCC7601. Molecular Microbiology. 1994; 13: 887-896.

39. Hong SJ, Lee CG. Statistical optimization of culture media for production of phycobiliprotein by Synechocystis sp. PCC6701. Biotechnology and Bioprocess Engineering. 2008; 13: 491-498.

40. Maurya SS, Maurya JN, Pandey VD. Factors regulating phycobiliprotein production in cyanobacteria. International Journal of Current Microbiology and Applied Sciences. 2014; 3(5): 764-771.

41. Poza-Carrion C, Fernadez-Valiente E, Fernadez-Pinas F, Leganes F. Acclimation of photosynthetic pigments and photosynthesis of the cyanobacterium Nostoc sp. strain UAM 206 to combined fluctuations of irradiance, $\mathrm{PH}$ and inorganic carbon availability. Journal of Plant Physiology. 2001; 158: 1455-1461.
42. Kaushik BD. Algalization of rice in salt-affected soils. Annals of Agricultural Research. 1994; 14: 105-106.

43. Roe S. Protein purification techniques: a practical approach. Oxford University Press, Oxford UK: ISBN 0-19-963674-5; 2001.

\section{How to cite this article:}

Onkar Nath Tiwari, Wangkhem Indira Devi, Chungkham Silvia, Angom Thadoi Devi, Gunapati Oinam, Oinam Avijeet Singh, Keithellakpam Ojit Singh, Thingujam Indrama, Aribam Subhalaxmi Sharma, Romi Khangembam, Minerva Shamjetshabam, Longjam Miranda, Radha Prasanna. Modulation of phycobiliprotein production in Nostoc muscorum through culture manipulation. J App Biol Biotech. 2015; 3 (04): 011-016. 